\title{
Corrigendum
}

\section{New Transitions from Human Rights to the Environment to the Rights of Nature}

\author{
Susana Borràs \\ doi:10.1017/S204710251500028X, published by Cambridge University Press, 22 January 2016.
}

First published online 2 August 2017

This article was published with two citations missing. The following sources were not sufficiently acknowledged (in particular on pages 116, 121, 124, 125 and 126):

- D.R. Boyd, The Environmental Rights Revolution: Constitutions, Human Rights and the Environment (University of British Columbia Press, 2012).

- D.R. Boyd, 'The Constitutional Right to a Healthy Environment' (2012) 54(4) Environment: Science and Policy for Sustainable Development, pp. 3-15.

The author acknowledges this error with regret and wishes to correct these omitted citations through this notice.

\section{REFERENCE}

S. Borràs, 'New Transitions from Human Rights to the Environment to the Rights of Nature' (2016) 5(1) Transnational Environmental Law, pp. 113-43. 